12-17 $\nabla 1997$ European Winter Conf. on Plasma Spectrochemistry, Gent, Belgium. L. Moens, Secretariat 1997 European Winter Conf., Laboratory of Analytical Chemistry, Univ. of Gent, Proeftuinstraat $86, \mathrm{~B}-9000 \mathrm{Gent}$ Belgium; 32-9-264-6600; fax 32-9264.6699; e-mail plasma97@ rug.ac.be.

\section{FEBRUARY 1997}

9-13 $\nabla 1997$ TMS Annual Meeting, Orlando, FL. TMS

Customer Service, 420

Commonwealth Dr., Warrendale, PA 15086; (412) 776-9000 ext 270; fax (412) 776-3770; e-mail csc@tms.org; World Wide Web http://www.tms.org.

28-4 IntI. Conf. on Materials and Mechanisms of Superconductivity-High-Temperature Superconductors, Beijing, People's Republic of China. M'S-HTSC V Secretariat, Cryogenic Laboratory, Chinese Academy of Sciences, P.O. Box 2711, Beijing 100080 People's Republic of China fax 86-10-2568834; e-mail zhao@aphy01.jphy.ac.cn.

\section{MARCH 1997}

6-8 $\nabla$ Intl. Workshop on Critical Currents in Superconductors for Practical Applications, Xi'an, China P.X. Zhang, Conf. Secretary, SPA '97. Northwest Inst. for Nonferrous Metal Research, P. 0. Box 51 Xi'an Shaanxi 710016 , P.R. China; $86-$ 29-6231079; fax 86-29-6231103; e-mail pxzhang@xitu.edu.cn.

10-12 $\nabla 1$ st ASM European Welding Science and Technology Cont., Madrid, Spain. ASM European Office, Blvd. St. Michel 15 , B-1040 Brussels, Belgium; 32-2-743-1546: fax 32-2-7431550; e-mail 100332.670@ compuserve.com

31-4 MRS Spring Meeting, San Francisco, CA. Materials Research Society, 9800 McKnight Rd. Pittsburgh, PA 15237-6006; (412) 3673003; fax (412) 367-4373. MRS.

\section{APRIL 1997}

7-10 Microscopy of Semiconducting Materials, Oxford, UK The Administrator, The Royal Microscopical Society, $37 / 38 \mathrm{St}$ Clements, Oxford OX4 1AU, UK: 44-1865-248768; fax 44-186579123

21-23 $\nabla$ Euromat 97: Materials, Functionality and Design, Maastricht The Netherlands EUROMAT 97, P. 0. Box 390, NL 3330 AJ Awijndrecht; 31-78-6192655; fax 31-78-619-5735; e-mail bvm@metropolis.ni.

\section{MAY 1997}

4-9 43rd Annual Meeting of the Inst. of Environmental Sciences, Los Angeles, CA. Inst. of Environmental Sciences, $940 \mathrm{E}$ Northwest Hwy., Mt. Prospect, IL 60056; (708) 255-1561; fax (708) 255-1699.

18-23 Conf. on Lasers and tronics and Laser Science Conf. Baltimore, MD. CLEO/0ELS ' 97 . Optical Society of America, 2010 Massachusetts Ave. NW, Washington, DC 20036-1023; (202) 223-0920; $\operatorname{tax}$ (202) 416-6100 Polar Engineering Conf., Honolu/u, HI. J.S. Chung, c/o Dept. of Engineering, Colorado School of Mines, 1500 Illinois St., Golden, CO 80401; (303) 273-3673; fax (303) $420-3760$.

\section{JUNE 1997}

9-14 25th Intl. Meeting on Chemical Engineering, Environmental Protection, and Biotechnology, Frankfurt am Main Germany. DECHEMA e V.

Ausstellungstagungen, Postfach 150104, D-60061 Frankfurt am Main, Germany; 49-69-7564-0; fax 49-69-7564-201. Electro-Optics/Quantum Elec

25-30 7th Intl. Oftshore and
15-19 4th Intl. Special Emphasis Symposium on Superalloys 718 625,706 , and Derivatives, Pittsburgh, PA. E.A. Loria, Alloy 718 625-706 Committee, 1828 Taper Dr.. Pittsburgh, PA 15241; (412) 221-5905; fax (412) 221-7355.

\section{AUGUST 199}

24-29 9th Intl. Meeting on Ferroelectricity, Seoul, Korea MF-9 Secretariat INTERCOM Convention Service, Inc., 4FI. Jisung Bldg., \#645-20, Yoksam

-dong Kangnam-ku, Seoul 135-081, Korea; 82-2-568-3208 tax 82-2-565-2434; e-mail

intercom@soback.kornet.nm.kr.

\section{SEPTEMBER 199}

7-10 6th Intl. Conf. on Ceramic Processing, Santa Barbara, CA. F.F. Lange, MRL, ENG II, Univ. of California at Santa Barbara, Santa Barbara, CA 93106: e-mail ceramics@mrl.ucsb.edu.

14-18 Conf. on Spectroscopies in Novel Superconductors, Cape Cod, MA. J. Pumphrey, Conf. Secretary, The Barnett Inst. Northeastern Univ., Boston, MA 02115; (617) 373-2868; fax (617) 373-2855. Conf., Rapid City, SD. L.

Kjerengtroen, S. Dakota School of Mines and Technology, Dept. of Mechanical Engineering, Rapid City, SD 57701; (605) 394-2409. fax (605) 395-2405; e-mail Ikjereng@msmailgw.sdsmt.

21-26 2nd Intl. Symposium on Structural Intermetallics, Champion, PA. B. Kamperman, The Minerals, Metals \& Materials Society, 420 Commonwealth Dr. Warrendale, PA 15086; (412) 7769000 , ext. 234; fax (412) 776 3770; e-mail kamperman@ tms.org.

\section{OCTOBER 1997}

11-17 OSA Annual Meeting, Long Beach, CA. Meetings Dept. Massachusetts Ave. NW, Washington, DC 20036-1023 (202) 223-0920; fax (202) 416 6100 .

13-15 $\vee 5$ th Intl. Symposium on Brittle Matrix Composites Warsaw, Poland. A.M. Brandt, IFTR, Swietokrzyska 21, 00-049 Warsaw, Poland; fax 48-22-

269815; e-mail abrandt@ ippt.gov.pl.
21-24 $\nabla$ Midwestern Mechanics Optical Society of America, 2010
14-18 $\nabla$ Radioactive Waste, Storage, Transportation. Human Impact, St. Petersburg. Russia. Shpalernaja str. 49. 193015 St. Petersburg, Russia; 7-812-274-3796; fax 7-812-274 1707; e-mail kkv@prometey2. spb.su, R-MAS, E-MRS.

\section{NOVEMBER 1997}

16-21 1997 Congress of the American Society of Mechanical Engineers, Dallas, $T X$ G.J. Wiens, Program Chair, Dept of Mechanical Engineering, 237 MEB, Univ. of Florida, Gainesville, FL 32611-6300; (904) 392-0806 fax (904) 392-1071, e-mail gwiens@cimar.me.ufl.edu.

\section{DECEMBER 1997}

\section{2-6 MRS Fall Meeting, Boston,} $M A$. Materials Research Society, 9800 McKnight Rd., Pittsburgh, PA 15237-6006; (412) 367-3003; $\operatorname{tax}(412) 367-4373$. MRS Recycling: Environment and

\section{CLASSIFIED}

\section{Positions Available}

\section{FACULTY POSITION IN APPLIED MECHANICS Stanford University}

The Applied Mechanics Division of the Mechanical Engineering Department of Stanford University invites applications for a tenure track faculty position at the Assistant Professor level in the general area of Mechanics and Materials. An eamed doctorate in Applied Mechanics, or in a closely related field of engineering or applied mathematics or solid state physics, is required, together with a proven interest and ability in the teaching of mechanics. The candidate's area of research interests should complement and enhance current research activities in the Division on the mechanics of micro- and nanostructures as well as related research activities in the Mechanical Engineering and Materials Science Departments. Applicants must have a strong foundation in solid mechanics together with interests in the applications of mechanics to engineering systems and materials. Preference will be given to candidates capable of establishing a strong theoretical research program complemented either by experimental investigations or by computational studies focused on the size scale at which lattice and continuum models overlap. The successful candidate must possess the ability to conduct creative independent research and must show strong promise for developing as an outstanding teacher.

Applicants should send a curriculum vitae, a 1-2 page statement of research and teaching interests and plans, and the names, addresses (postal and e-mail) and telephone numbers of at least three referees to:

Chair, Applied Mechanics Faculty Search

Division of Applied Mechanics

Durand Building

Stanford University

Stanford, CA $94305-4040$

Applications received by July 31, 1996 will be given full consideration, but the search will remain open until the position is filled.

A copy of this advertisement appears on the World Wide Web at http://cdr.stanford.edu/ME/Announcement/Faculty position.html with links to the home pages of Mechanical Engineering and the Applied Mechanics Division at Stantord.

Stanford University is an Affirmative Action Employer seeking to increase representation of minorities and women among its faculty. As such, applications from female and minority candidates are strongly sought and encouraged. 


\section{Positions Available}

\section{CHAIRPERSON \\ Materials Science and Engineering Department lowa State University}

The Materials Science and Engineering Department (MSE) at lowa State University invites applications and nominations for the position of Chairperson. Candidates must have an eamed doctorate in one of the fields of Materials Science and Engineering with demonstrated professional achievement in teaching and research sufficient to qualify for the rank of tenured professor. Candidates should also have successful academic and/or industrial administrative experience.

lowa State University has rapidly growing research programs with heavy emphasis on materials research. Significant support of MSE faculty members already exists in five campus centers: The Ames Laboratory of the Department of Energy, The Center for Advanced Technology and Development, The Center of Nondestructive Evaluation, The Microelectronic Research Center, and The Engineering Research Institute. The new chairperson will have the opportunity to build on this strong foundation in leading the department's response to new direction in Materials Science and Engineering.

The MSE department has 16 full-time faculty members and five adjunct faculty members from various research centers. The BS degree is offered in Ceramic Engineering and in Metallurgical Engineering and the MS and $\mathrm{PhD}$ degrees are offered in Materials Science and Engineering. Undergraduate enrollment varies from 80 to 100 students. There are currently 55 graduate students enrolled. The chairperson will be expected to continue the department's strong emphasis on undergraduate teaching and expand its efforts in research and outreach. Enhancement of ties with industry and government agencies is a high priority.

Applications with resumes that include names, addresses and telephone numbers of three references should be submitted to Dr. Maurice A. Larson, Chair; MSE Search Committee; 2114 Sweeney Hall; lowa State University; Ames, IA 50011-2230. Nominations are also desired. Review of applications will begin on July 1,1996 , and continue until the position is filled. It is hoped that the position can be filled by January 1, 1997.

lowa State University is an equal opportunity/ affirmative action employer.

\section{RESEARCH SCIENTIST Honeywell}

The Honeywell Technology Center (HTC) is a multidisciplinary industrial R\&D Center involved in innovative $R \& D$ projects in the areas of sensors, microelectronics, controls, signal processing and software. Currently, we have the opportunity available for a Research Scientist.

In this vital role, you will be responsible for the advanced development of III-nitride materials for use in novel wide band-gap devices. We will rely on you to provide leadership to material growth specialists, coordinate activists of wide band-gap semiconductor device designers, and interact with microsensor scientists and technicians.

The qualified candidate will have an advanced degree in materials science or electrical engineering (PhD preferred) and experience with development of wide band-gap semiconductor materials. Experience in metal-organic chemical vapor deposition growth is desirable.

In retum for your expertise, we offer a competitive salary/benefits package and a stimulating technical environment. For confidential consideration, please send/tax your resume and salary requirements to:

Honeywell Technology Center

Esther Saarela

3660 Technology Drive

Minneapolis, MN 55418

Fax: 612-951-7181

Equal Opportunity Employer M/F/DN

\section{POSTDOCTORAL POSITION Ion-Solid Interactions Oak Ridge National Laboratory}

The Oak Ridge National Laboratory (ORNL) invites applications for a postdoctoral position in the Ion-Solid Interactions Group of the Solid State Division beginning December 1996. The mission of this group is materials-oriented and involves ion beam synthesis or modification of materials to produce novel and technologically relevant properties. Research in which the successful candidate will be involved includes the formation of nanocrystals and quantum dots in insulators to produce unique optotelectronic responses; synthesis of buried layers in semiconductors for interconnect or isolation applications; and the physics of ion-induced defects in semiconductors. The diverse scope of this program and the interactions it has fomented with other national laboratories, industry, and universities will provide the successful candidate a unique opportunity for professional growth. Candidates should be recent PhD graduates in physics, metallurgy, or materials science with a strong background in materials characterization. Excellent verbal and written communication skills required. Prior experience using transmission electron microscopy is essential. The position is for one year with possible renewals for up to two additional years. Applicants should send resume, including publication list, ar,d the names of three references by August 1, 1996, to:

C.W. White

Solid State Division

Oak Ridge National Laboratory

P.O. Box 2008

Oak Ridge, TN 37831-6057

ORNL is an equal opportunity employer committed to building and maintaining a diverse work force.

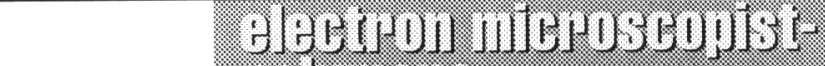 131) 11111313}

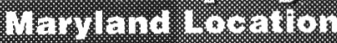

W.L. Gore \& Associates, Inc., named as one of "The 100 Best Companies to Work for in America" and recognized as a progressive, high technology company, offers unique opportunities for career growth. We are a global leader in fluoropolymer technology and have diversified products in electronic, industrial, medical and GORE-TEX fabrics applications. W.L. Gore is a privately held corporation with technology and manufacturing facilities clustered in Delaware, Maryland, Europe and Japan.

There is an immediate opportunity for an Electron Microscopist at one of our Maryland facilities.

\section{Responsibilities:}

- Build a state-of-the-art analytical electron-optics facility

- Develop methods for analytical characterization of polymers

- Develop methods for high resolution

imaging of polymers using both SEM and TEM

- Pull together a global team focused on electron-optics characterization

- Teach analytical electron-optic

Please send or fax resume to:

\section{W.L. GORE \&} ASSOCIATES, INC.

Attn: $\mathrm{CH} 1738$

P.O. Box 9206

Newark, DE 19714-9206

Fax: (302) 292-4156

Equal Opportunity Employer characterization to other Gore associates

\section{Requirements include:}

- Advanced degree in sciencel engineering with a strong materials/ polymer background

- Minimum of five years extensive hands-on industrial experience on SEMs and EDS/WDS

- Extensive experience with sample preparation techniques and imaging of synthetic polymers

- Demonstrated experience with quantitative image analysis - Hands-on experience with TEMs - Experience with statistical design of experiments

- Excellent interpersonal skills with proven record of working in a team environment

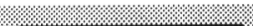

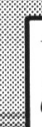
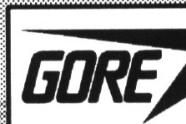